\title{
Diversity from the Inside Out: Eight Years of the UNCG Libraries Diversity Committee
}

$\mathrm{T}$ The Diversity Committee of UNC-Greensboro Libraries, founded in 2007, develops and supports activity relating to diversity and inclusion. Recognizing that the most successful change begins from within, the Committee's strategy for promoting diversity began with internal library staff development, and expanded over time to international representation of library faculty. Examples of diversity-related programs undertaken by the committee range from staff development focused on providing support to unique populations on campus, to the creation of the Diversity Resident Librarian position. In this article, members of the UNC-Greensboro Libraries Diversity Committee will discuss the programs that this committee developed and sponsored, beginning with training from within the Libraries for staff, expanding to regional, national, and international representation.

\section{Diversity and Institutional History: An Introduction}

The University of North Carolina at Greensboro (UNCGreensboro) enjoys the reputation as an institution that embraces values of diversity and inclusion. Originally chartered as the State Normal and Industrial School for White Girls in 1891(McIver Records), ${ }^{1}$ UNC-Greensboro presently stands among the top three of sixteen UNC higher education campuses in terms of highest population of ethnic minority students. Additionally, twelve percent of the student body self-identify as LGBTQ. With such a varied student body, the University Libraries of UNC-Greensboro actively seeks ways to understand and meet the needs of its primary patron population.

UNC-Greensboro Libraries formed an Ad Hoc Committee on Exploring Diversity Issues, which released a report in 2007, including several suggestions on how to best meet the needs of students and promote an inclusive institutional environment within the Libraries. Among the proposed recommendations was the development of a Diversity Coordinator position, which would serve as chair of an official University Libraries (UL) Diversity Committee. Reference Librarian, Gerald Holmes was appointed to this position, and the official UL Diversity Committee was formed in 2008. The UL Diversity Committee was among the first committees on the entire UNC-Greensboro campus created for the principle purpose of addressing diversity issues. In fact, being among the first of such committees, the UL Diversity Committee supported the establishment of the UNC-Greensboro Chancellor's Advisory Committee on Equity, Diversity, and Inclusion, which formed in 2009.

\section{From the Inside: Staff Development}

When the UL Diversity Committee initially met in 2008, members agreed that for an institution to earn attention as an ally and promoter of diversity and inclusion at the community, national, and international levels, such standards must be entrenched as part of the work ethic of library employees. This necessitated that the Committee establish staff development opportunities, which would promote equity, diversity, and inclusion as fundamental values to be considered and applied to staff and faculty work in all library departments. The Committee identified two staff development objectives to strengthen these values within the library: 1) cultivate an inclusive environment by opening dialog among employees, and 2) develop skills and crosscultural competencies that can be incorporated into daily workflows.

Although "cultivating an inclusive environment by opening dialog" sounds as though it should be the easiest to accomplish of all the proposed goals, it is deceptively difficult to implement in a practical manner. First, one must entice people into a conversation (no small feat for introverted library-types). Additionally, topics of discussion may involve volatile issues, in which people may be afraid of offering their opinion for concern of hurting someone's feelings, or conversely, some individuals may over-share their perspective, thus alienating everyone in the process. Finally, creating an inclusive environment for library employees means establishing that everyone benefits from the promotion of equity and diversity, which can be challenging to persuade a homogenous workforce.

The UL Diversity Committee organized two types of events to promote dialog among library staff. Among the most popular of these was the UL Diversity Movie Series. The movie series features a video about some aspect of diversity followed by a discussion among attendees. The first of such films shown was Voices of North Carolina (2005), 
a documentary highlighting the richness of linguistic diversity throughout the state. This served successful for initial "buy-in" of support from library employees, as everyone has a dialect or accent, so all staff could relate to this aspect of diversity. In addition to the movie series, the UL Diversity Committee sponsors "Lunch and Learns," in which staff are encouraged to spend their lunch break listening to presenters from within the Libraries or externally speak on a topic of some relevance to diversity. An example of a typical "Lunch and Learn" includes a panel discussion held by Middle Eastern students, describing and discussing the differences between libraries in their home countries and the libraries in the United States. As UNC-Greensboro supports a large international student presence, including a substantial body of Middle Eastern students, the program was both enlightening about cross-cultural practices and of practical application in understanding the knowledge barriers Middle Eastern students may experience when accessing UNC-Greensboro Libraries.

\section{The University Libraries holds a unique} position in being able to address and support the needs of campus students, faculty, and staff... 99

The second objective of the UL Diversity Committee was to develop the diversity and inclusion skillsets of library employees through specialized training and cultural competency programs. In order to incorporate such specialized training for staff, the UL Diversity Committee collaborated with various offices on campus, including the Office of Accessibility Resources and Service and UNC-Greensboro Safe Zone (the LGBTQ education trainers). UL Diversity Committee has organized workshops for library staff relating to supporting a wide variety of patrons, such as those with mobility issues, learning challenges, speech and communication challenges, LGBTQ students, and students at high risk. Such training educates library staff in better understanding the needs of these students and provides practices that can be incorporated into daily work routines. When these workshops are held, the Committee schedules at least three sessions at different times of the day to make certain day and evening staff can attend.

\section{Expanding from the Library to the Campus} The UL Diversity Committee seeks not only to promote the values of diversity, equity, and inclusion among library staff, but strives to be known as a leader in engaging the UNC-Greensboro campus community on these issues. The University Libraries holds a unique position in being able to address and support the needs of campus students, faculty, and staff, seeking to publicize relevant services and resources. The committee raises campus visibility of the Libraries' diversity initiatives by creating information resources and providing educational presentations. Committee members create research guides, aggregating library, campus, and online resources devoted to relevant issues. Among the research guides maintained by committee members are those for Accessibility Resources and Services $^{2}$, Bullying ${ }^{3}$, and Safe Zone ${ }^{4}$. Additionally, as diversity is an emphasized facet of the Libraries' strategic plan, library faculty and staff in departments that perform outreach frequently provide education presentations. These presentations range from information literacy and research techniques to institutional history. Presentations relating to diversity in institutional history are particularly popular. These include sessions on the history of African Americans on campus, the history of the LGBTQ community on campus, and the history of students with disabilities on campus.

\section{Expanding from the Campus to the Community}

While the UL Diversity Committee has spearheaded a number of campus-based programs, expanding to the community is deemed equally as important. In October of 2009 the Diversity Committee presented a panel at the North Carolina Library Association (NCLA) annual conference. The title of the presentation was "The Library Diversity Committee: Serving Knowledge, Serving You." The goals of the presentation were to educate librarians and administrators on the benefits and process of creating a diversity committee at their libraries, to help generate ideas for programming, and to assist in identifying collaboration opportunities to the greater campus community and beyond.

In 2008, the University Libraries hosted two librarians from the Shanghai University of Finance and Economics (SUFE) Library in China. The librarians participated in several outings and events including a visit to Claxton Elementary School in Greensboro. The librarians presented to three classes of second and third-graders about life in China and Chinese culture.

In December of 2010, the Diversity Committee along with other UL librarians held a holiday drive in which school supplies and monetary donations were collected to help support Hampton Leadership Academy in Southeast 
Greensboro. Hampton Leadership Academy, an elementary/university partnership magnet school, partnered with North Carolina Agricultural and Technical State University (NCA\&T) in 2010. Hampton encourages an educational environment in which students are challenged, excellence is expected, differences are valued, and exposure to higher education is integrated into the culture of the school. Three boxes and $\$ 106.66$ of school supplies were collected and delivered to Hampton in January, 2011.

Throughout all of the community initiatives, the Academic and Cultural Enrichment (ACE) Scholars have played an active role. The ACE Scholars Program is a collaborative effort between UNC-Greensboro and nine other academic libraries in North Carolina that was created to increase cultural diversity amongst graduating librarians. The initiative, which was funded by the Laura Bush 21st Century Library Grant, assists with the recruitment, mentorship and support of members of under-represented communities in the United States in their pursuit of a Masters of Library and Information Science (MLIS) degree. Past ACE Scholars have assisted with campus and community events and have presented at several local and national conferences. Graduates have gone on to serve as library media specialists, education librarians, fine arts librarians, instructors, youth services librarians, reference librarians, and doctoral candidates at prestigious universities.

\section{Diversity Residents' National Contributions}

Since the inception of the Diversity Resident Librarian position, UNC-Greensboro Libraries have hosted and mentored four diversity residents. A diversity resident is an early career librarian from an underrepresented group who has recently received the MLIS degree from a program accredited by the American Library Association. The residency program is mutually beneficial. The resident will grow and development professionally; in return, the library will benefit from special skills, ideas and initiatives of the new librarian. The length of residency programs varies depending on institution. At UNC-Greensboro, each resident serve a two year appointment, however, programs typically range from 1-3 year appointments.

During their appointments, all four residents made significant contributions to the library profession both locally and nationally. The first diversity resident, Jason Alston, was appointed in spring of 2008. He served on the Executive Board of the Black Caucus of the American Library Association. He also served as logistical co-chair for the planning of the National Conference of African American Librarians in 2010. The second diversity resident, LaTesha Velez, served from 2010-2012. She presented at three doctoral recruitment webinars hosted by ALA's Office for Diversity. Nataly Blas, was the third diversity resident from 2012-2014. She is the current convener for ACRL Residency Interest Group. Orolando Duffus is the current diversity resident librarian for 2014-2016. He co-presented with four other former and current residents at the annual conference of the American Library Association in June, 2015. He spoke about his diversity initiatives (including a Diversity Expo that he planned) at UNC-Greensboro and advocated for residencies by sharing some mutual benefits that have resulted from his experience.

\section{Diversity Initiative: Diversity and Global Engagement Expo}

As libraries across the globe are making a firm commitment to support diversity, librarians are adopting and supporting new services and programs that attract diverse users. Since the appointment of a permanent Library Diversity Committee in 2007, the University Libraries at UNC-Greensboro have been re-emphasizing a commitment to diversity.

With the support of the UL Diversity Committee, the current Diversity Resident Librarian decided to create a more interactive and student centered library outreach initiative in the form of a Diversity Expo. He invited student organizations including numerous multicultural student groups into UNC-Greensboro's main library to share their initiatives, collaborate with other organizations and recruit new members. The event created a spotlight for the multicultural students groups which enabled them to generate lots of membership interest. It gave new and existing students an opportunity to learn about and join various student organizations while engaging in the diversity on campus. Students love that they were able to learn about other cultures, sample exquisite cuisines and listen to global melodies while cultivating shared experiences.

A survey methodology was used to collect data from participants at the Expo. The survey responses helped to identify some critical areas that the Libraries needed to improve in order to create a more welcoming and inclusive library environment. We learned that aesthetics or sensory cues weigh heavily on students' perceptions of the library and their willingness to approach librarians. Students, both foreign and local, indicated that visual cues such as multinational flags/banners and artifacts of cultural or historical significance are helpful in reducing anxiety and creating a sense of belonging.

The event was well attended by over two hundred students with participants representing all inhabited continents. Most of the survey respondents (53\%) indicated that they were a native of a country other than the United 
States. In addition, just over $60 \%$ of the respondents indicated that they learned something new about another culture. This speaks volumes to the level of cultural diversity and interactions and prompted participants to request that the event continue annually.

The event concluded with a panel discussion where students, student leaders and members of UNC-Greensboro's administration and faculty convened to discuss global issues affecting society. The panelists included the department heads of the sponsoring units and were moderated by an associate professor representing the Department of African American and African Diaspora Studies. The Diversity Expo was extremely successful mainly due to the contributions of numerous campus organizations. These organizations were instrumental for funding, promotion, and program ideas. Diversity dialogues are beneficial for libraries because they creates an atmosphere where students, faculty and staff can learn from other members of the university community, work through assumptions and biases that might affect work performance, and workplace interactions, not only with staff but with library patrons. ${ }^{5}$

This outreach initiative has resulted in long-term collaborations among students, faculty and staff. It is low cost and the time commitment is comparative to planning a book swap. The return on investment is exponential, since it provides an opportunity to market library products and service, create strategic alliances or partnerships with stakeholders, create advocates, and expand the library's outreach efforts.

\section{International Partnerships and Presentations}

Libraries all over the world are facing many of the same challenges related to collection management, human resource management, and more. It is imperative that librarians build relationships with librarians in other countries to enhance user experience in our libraries. The benefits of these exchanges could include sharing information about best practices, exchanging materials and expertise, and working together on mutually advantageous projects.

The University Libraries have been encouraging these exchanges by hosting visiting scholars and supporting international travel for librarians annually. The University libraries have hosted several visiting librarian scholars from countries such as China and Moldova. The visiting librarians interacted with library faculty and staff (both in the library and Library and Information Studies department), exchanged their work experience, shared library best practices, and presented sessions on library projects in their countries.
Many of our librarians attended and presented at international conferences such as the International Federation of Library Associations and Institutions (IFLA). One of our librarians was invited to China as a part of the "Think Globally, Act Globally” project. In 2012, Beth Filar Williams, our former Distance Education Librarian, was invited as a guest lecturer at the Digital Libraries Learning (an international Master's program for "elite information professionals") program in Norway. ${ }^{6}$ She then presented with the group in Italy and Estonia. Most recently, in September 2015, three members of UNC-Greensboro's Special Collection and University Archives spoke on a panel at the Women's History Network Annual Conference in Canterbury, UK. The tile of their presentation was "Behind the Lines: Mobilization \& Activism of American Women in the Great War," which highlighted women's socio-economic and political contributions to the Great War. Many librarians have made significant contribution to international librarianship via presentation and or committee work since the establishment of the Diversity Committee in 2007.

The Library Diversity Committee is currently in the second year of the University Libraries' five year Strategic Diversity Plan. The goals of the plan include creating and sustaining a welcoming, supportive and inclusive campus climate; developing programming and outreach for the Libraries and the community in support of diversity; supporting diversity in the UNC-Greensboro curriculum; creating a library environment that reflects diversity; preparing UNC-Greensboro students to live and work in a diverse global world; and developing and executing a comprehensive Diversity and Inclusive Communication Plan. The Libraries' Diversity Committee records and monitors its progress and reports it annually.

\section{Conclusion}

From its inception in 2007 as an Ad Hoc Committee, the UNC-Greensboro UL Diversity Committee has grown considerably. Its impact has expanded across campus, the Greensboro community, the state of North Carolina, and across the globe. By committing time and energy to fostering diversity in librarianship, engaging others in thoughtful discussion, and lending support to similar initiatives, UL Diversity Committee has been able to leave its mark. As the UL Diversity Committee moves forward with new programs and initiatives, it aims for continued progress and success. 


\section{References}

1 "Bill to Establish the Normal Industrial School", UA2.1 Charles Duncan McIver Records, 1855-1906, Martha Blakeney Hodges Special Collections and University Archives, University of North Carolina at Greensboro, NC, USA.” 2015. Accessed December 29. http://libcdm1.uncg.edu/cdm/ref/collection/ui/id/7324.

2 Minerva, Irma. 2015. “Research Guides: Accessibility Resources and Services: Home.” Accessed December 29. http://uncg.libguides.com/accessibility_services.

3 Holmes, Gerald. 2015. "Research Guides: Bullying: Home.” Accessed December 29. http://uncg.libguides. com/c.php?g=83306.

4 Krim, Stacey. 2015. “Research Guides: Safe Zone Resources: Home.” Accessed December 29. http://uncg. libguides.com/safezone.

5 Winston, Mark. 1999. Managing Multiculturalism and Diversity in the Library: Principles and Issues for Administrators. Psychology Press.

6 "Study online or on campus." Oslo and Akershus University College. last accessed December 30, 20015. http://dill. hioa.no/programme/.

\section{North Carolina Libraries}

Official Publication of the North Carolina Library Association

ISSN 0029-2540

All issues are available online free-of-charge at

Back issues are available from the North Carolina Library Association office at 1811 Capital Blvd., Raleigh, NC 27604 , for $\$ 8$ an issue for those years prior to going online in 2002, or $\$ 50$ for the annual print compilation beginning with Vol. 60 (2002).

\section{Looking for help with collection development?}

If you want to expand your library's collection of novels set in North Carolina, you should visit the Read North Carolina Novels blog hosted by the North Carolina Collection at the University of North Carolina at Chapel Hill (http://blogs.lib.unc.edu/ncnovels/).

If your interest in North Caroliniana is more general, the North Carolina Collection at UNC-Chapel Hill regularly posts lists of new additions to their collection at this address: http://blogs.lib.unc.edu/ncm/index.php/ whats-new-in-the-north-carolina-collection/. 